\title{
FERNANDO SABINO: TRADUTOR DE DOM CASMURRO
}

\author{
Jefferson Luiz Franco*
}

Também afirmava que das diversas felicidades que pode ministrar a literatura, a mais alta era a invenção. Já que nem todos são capazes desta felicidade, muitos terão de contentar-se com simulacros. Jorge Luis Borges - Exame da obra de Herbert Quain

$\mathrm{N}$ o conto "Pierre Menard, autor do Quixote", Jorge Luís Borges traz à tona uma iniciativa que, como é expresso no fechamento do texto, enriqueceu, mediante uma técnica nova, a arte retardada e rudimentar da leitura: a técnica do anacronismo deliberado e das atribuições errôneas. Seria Amor de Capitu a realização prática do projeto de Menard? Através do anacronismo deliberado de reconstruir o texto machadiano e das atribuições errôneas existentes nessa nova narrativa Fernando Sabino estará dando seu próprio polimento à arte da leitura?

Para responder a esta questão vamos utilizar as ferramentas que o próprio Borges nos cedeu, através da comparação direta dos textos, como no trecho a seguir:

Constitui uma revelação cotejar o Dom Quixote de Menard com o de Cervantes. Este, por exemplo, escreveu (Dom Quixote, primeira parte, nono capítulo):

* Universidade Federal do Paraná. 


\begin{abstract}
...a verdade, cuja mãe é a história, êmulo do tempo, depósito das ações, testemunha do passado, exemplo e aviso do presente, advertência do futuro.

Redigida no século XVII, redigida pelo engenho leigo, Cervantes, essa enumeração é um mero elogio retórico da história. Menard, em compensação, escreve:

...a verdade, cuja mãe é a história, êmulo do tempo, depósito das ações, testemunha do passado, exemplo e aviso do presente, advertência do futuro.

A história, mãe da verdade; a idéia é espantosa. Menard, contemporâneo de William James, não define a história como uma indagação da realidade, mas como sua origem. A verdade histórica, para ele, não é o que sucedeu; é o que pensamos que sucedeu. As cláusulas finais exemplo e aviso do presente, advertência do futuro - são descaradamente pragmáticas. (Borges, 1999, p. 56)
\end{abstract}

Vejamos agora o engenho leigo de Machado de Assis em ação no capítulo 49 de Dom Casmurro:

A casa, na minha opinião, não devia ser grande nem pequena, um meio-termo; plantei-lhe flores, escolhi móveis, uma sege e um oratório. Sim, havíamos de ter um oratório bonito, alto, de jacarandá, com a imagem de Nossa Senhora da Conceição. Demorei-me mais nisto que no resto, em parte porque éramos religiosos, em parte para compensar a batina que eu ia deitar às urtigas; mas ainda restava uma parte que atribuo ao intuito secreto e inconsciente de captar a proteção do céu. Havíamos de acender uma vela aos sábados... (Machado de Assis, 1983, p. 83 - sem grifos no original)

Descendo às minúcias como fez Borges, que podemos depreender deste apego maior do narrador Bento Santiago à descrição do oratório com que sonhava mobiliar sua futura casa? Não é preciso que nos delonguemos em busca da resposta: eis que nossa própria e pobre edição da obra, destinada a secundaristas, 
nos traz a sugestão: "compare esta preocupação religiosa com o que aconteceu nos capítulos 20 e 27" (Machado de Assis, 1983, p. 201). Para quem não se lembra, estes incluem os mil padres-nossos e a esmola dada em troca de orações. Não é preciso ir muito longe para perceber que tal sugestão, desnecessária ao leitor atento, vai minando o crédito que depositamos não apenas na religiosidade, mas na confiabilidade de nosso Bentinho, que não hesita em distorcer suas promessas celestes ao seu comportamento terrestre. Notemos, também, que o narrador diz demorei-me, dando a entender que Bento Santiago mencionou e deteve-se sobre o oratório e, para tanto, se justifica perante si mesmo e perante seu leitor:

em parte porque éramos religiosos, em parte para compensar a batina que eu ia deitar às urtigas; mas ainda restava uma parte que atribuo ao intuito secreto e inconsciente de captar a proteção do céu.

Comparemos isto atentamente ao narrador de Amor de Capitu:

Eles se detiveram imaginando tudo isso, em parte porque eram religiosos, em parte para compensar a batina que ele ia a tirar às urtigas. Restava o intuito secreto e inconsciente de captar a proteção do céu. Haviam de acender uma vela aos sábados... (Sabino, 1998, p. 85)

Quem se deteve? Eles. Quem é justificado? Também eles. A vela aos sábados se torna decisão mútua e conjunta, capaz de enredar a vizinha Capitolina nas promessas de Bento, ambos cúmplices ante o céu.

O que Machado nega a Bentinho que Fernando Sabino concede a este mesmo personagem? O sonho de qualquer causídico: a vitória de seu cliente não pela imposição de sua opinião pessoal, mas, sim, e antes de tudo, pela demonstração de uma verdade objetiva e irrefutável, diante da qual a dama cega não possa oferecer hesitações. 
Quanto a essa suposta objetividade do narrador de Sabino, vamos retomar uma noção básica e quase óbvia que Décio de Almeida Prado utiliza para tipificar um dos diversos tipos de narrador romanesco no ensaio "A personagem no teatro": 1

O narrador, por excelência, talvez seja o dominante no romance do século XIX, o narrador impessoal, pretensamente objetivo (...). Ele está em todos os lugares ao mesmo tempo, abarca com o seu olhar a totalidade dos acontecimentos, o passado como o presente, é ele quem descreve o ambiente, a paisagem, quem estabelece as relações de causa e efeito, quem analisa os personagens (revelando-nos coisas que às vezes eles mesmos desconhecem). (p. 86)

O narrador de Sabino nos revela, realmente, algo que a própria Capitu desconhece e que nem mesmo seu futuro marido ousou explicitar, ou seja, sua co-participação na promessa interesseira de Bento Santiago. Será que isso combina com o subtítulo "leitura fiel do romance de Machado de Assis sem o narrador Dom Casmurro"? Os pés de barro da fidelidade de Sabino são muito mais explícitos e inquestionáveis que os de Capitu. Aliás é de se questionar: é possível uma leitura fiel de Dom Casmurro sem Bentinho? Aliás, é possível existir aquela que se possa determinar de leitura fiel?

Estaríamos antes inclinados a substituir o termo "leitura fiel" por "paródia pós-moderna" conforme concebida por Linda Hutcheon na sua Poética do pósmodernismo:

...quando falo em "paródia", não estou me referindo à imitação ridicularizadora das teorias e das definições padronizadas que se originam das teorias de humor do século XVIII. A importância coletiva da prática paródica sugere uma redefinição da paródia como uma repetição com distância crítica que permite a indicação

1 PRADO, Décio de Almeida. A personagem no teatro. In: CANDIDO, Antonio. (Org.). A personagem de ficção. São Paulo: Perspectiva, 1968. 
irônica da diferença no próprio âmago da semelhança. $\mathrm{Na}$ metaficção historiográfica, no cinema, na pintura, na música e na arquitetura, essa paródia realiza paradoxalmente tanto a mudança como a continuidade cultural: o prefixo grego para pode tanto significar "con-tra" como "perto" ou "ao lado". (Hutcheon, 1991, p. 88)

Será que é possível enxergar dentro de Amor de Capitu um exercício não-ingênuo de prática irônica em relação ao original de Machado? O que a eliminação das marcas mais óbvias (pois, como podemos ver em qualquer curto trecho, permanecem intocadas as mais significativas) do narrador Bento Santiago estabelece na obra? A princípio poderíamos afirmar que ela impõe, também nas palavras de Linda Hutcheon, o ex-cêntrico que, tanto como off-centro como quanto descentralizado passa a receber atenção.

Mas poderemos realmente afirmar isto em relação ao romance de Sabino? Cremos que qualquer dos leitores do livro há de concordar que Bentinho mantém, ainda, sua posição narrativa privilegiada para elaborar seu auto jurídico ao belprazer, senão, vejamos este trecho em que nosso narrador neutro descreve a personalidade do filho de Capitu:

Ezequiel não faria assim. Não arranjaria bolas envenenadas, mas também não as recusaria ao cachorro. O que faria, certamente, era ir atrás dos cães, a pedradas, até onde as pernas o levassem. (p. 176)

Enquanto Bentinho diz:

Tal não faria Ezequiel. Não comporia bolas envenenadas, suponho, mas não as recusaria também. O que faria com certeza era ir atrás dos cães, a pedrada, até onde lhe dessem as pernas. (cap. 112) 
Estranhamente é o pai que dá a Ezequiel o benefício da dúvida. É a palavra, suponho, que guarda, como o frágil guard-rail que separa nosso trem do descarrilamento sobre o abismo, a peremptoriedade incontestável de Sabino da fina trama de suspeita, insinuações e inverdades composta por Machado. É na dúvida que paira sobre a cabeça do narrador, espada de Damócles eternamente ameaçando rechaçar a causa tão bem construída de nosso jurista, que está a composição quase etérea da obra e que inexiste em Fernando Sabino. Em Amor de Capitu qualquer dúvida quanto à lisura do narrador é abolida pela supressão.

Hélio Pólvora, falando sobre Helen Caldwell, ${ }^{2}$ nos conta que, na crítica que fez a $O$ Primo Basílio, Machado escreveu que a substituição do que é acessório pelo principal, a transferência da ação, da natureza e sentimentos das personagens para acontecimentos fortuitos, parecia-lhe incompatível, senão contrária, com os princípios da arte. O lenço de Desdêmona tem muito a ver com a sua morte, mas a alma ardente e ciumenta de Otelo, a perfídia de Iago e a inocência de Desdêmona são os principais elementos da ação.

Pois bem, segundo Pólvora, o modelo da tragédia shakespereana estaria reproduzido em Dom Casmurro, onde o lenço de Desdêmona seria a semelhança, ou presunção de semelhança, de Ezequiel com Escobar. Seguindo a fórmula de Machado para a ação dramática, Caldwell conclui, por antecipação, que o drama está nas naturezas, paixões e condição espiritual de Otelo-Santiago, Iago-Santiago e Desdêmona-Capitu; a semelhança entre Ezequiel e Escobar não controla esses três personagens, de cujas paixões flui a ação.

E daí se conclui, que, afinal, essencial na tragédia de Otelo é Otelo, Iago, Desdêmona e não o lenço. Mais: que por mais que se tente apagar, Otelo é este trio, e não o lenço, que dá vida ao texto e que uma tentativa off-centro de colocar o lenço acima de Otelo é, no mínimo, destinada ao objetivo deplorado pelo já citado Pierre Menard: produzir o prazer plebeu do anacronismo - no caso, impingindo ao romance de Machado um narrador verdadeiramente dezenovista no pior sentido da palavra e propugnando uma neutralidade inexistente e, de qualquer forma, empobrecedora.

Até aí não se entra, no entanto, no que se esconde por trás de Amor de Capitu.

Uma vez definido que a obra não é, realmente, uma técnica nova para a rudimentar arte da leitura e tampouco uma paródia pós-moderna, o que ela seria? Propomos que o texto de Sabino passe a ser encarado como uma tentativa desastrada de exercer outra arte que não exatamente a escrita: a tradução. A

2 Disponível em: <http://www.secrel.com.br/ jpoesia/polvra04.html> 
favor de tão tresloucada opinião, lembremos que ao próprio fictício Menard foi dada primeiramente uma veia de tradutor (afiada com López de Segura e Quevedo) antes de Borges levá-lo além dos limites desta atividade (primeiro com o texto de Valéry e a seguir com o Quixote). Estabelece-se aí, portanto, um elo de causa e conseqüência no texto borgeano - seria possível um Menard autor do Quixote sem um Menard tradutor de Quevedo?

Mas, afinal, qual é o conceito de tradução a que nos prenderemos? Utilizemos aquele exemplificado em Walter Benjamin: tradução e melancolia, de Susana Kampff Lages, que, discorrendo a respeito da representação iconográfica da Melancolia executada por Albrecht Dürer, cita E. Panofski, que acredita que o pintor e gravurista criou uma representação simbólica, numa harmonização entre o plano concreto e abstrato da representação (Lages, 2002, p. 42), sendo por isso uma tradução eficiente, que não cinde a concretude e o intangível. Daí se origina, também, nossa observação de que Fernando Sabino fez uma tentativa de tradução, pois a concretude que batalhou para oferecer aos seus leitores em Amor de Capitu foi estabelecida às custas do sacrifício do elemento de intangibilidade da obra original de Machado.

E a quem se destina a tradução de Dom Casmurro empreendida pelo mineiro? Peço licença para uma longa citação, que, espero, venha lançar luz sobre a questão:

O iluminismo dissolve a injustiça da antiga desigualdade, a dominação imediata, porém torna-a, ao mesmo tempo, eterna mediação universal, na relação de um ente qualquer a qualquer outro. Ele consegue fazer aquilo de que se louva a ética protestante de Kierkegaard e que se encontra no ciclo épico de Hércules como um dos arquétipos da violência mítica: ele extirpa o incomensurável. Não só as qualidades que se dissolvem no pensamento, também os homens são coagidos à conformidade com o real. O mercado não questiona sobre o seu nascimento, mas o preço dessa vantagem, pago por quem fez a troca, foi o de ser obrigado a permitir que as suas possibilidades de nascença fossem modeladas pela produção das mercadorias que nele podem ser compradas. (Adorno, 1996, p. 28) 
A citação provém do Conceito de Iluminismo, de Adorno e Horkheimer, e é para esse ser, contemporâneo de um iluminismo que nunca se desfez totalmente, segundo os autores, que Fernando Sabino tenta traduzir a obra de Machado. Assim, a extirpação do incomensurável - em sua acepção mais clara (aquilo que não se pode medir e é, conseqüentemente, intangível e que, portanto, questiona seu próprio nascimento como narrativa confiável) - não somente é um procedimento aceito, como, também, obrigatório em um mercado no qual a mediação entre ente e ente ou ente e objeto é considerada a via de regra.

\title{
RESUMO
}

Neste estudo, o texto de Fernando Sabino, Amor de Capitu, é submetido ao crivo do indefectível Borges, mais precisamente à teoria formulada em "Pierre Ménard, autor do Quixote", para concluir que a obra em questão deve ser considera antes uma "tradução" do que uma "escrita".

Palavras-chave: fição histórica, metaficção, Fernando Sabino.

\begin{abstract}
In this study the novel Amor de Capitu, written by Fernando Sabino, is submitted to the indefective Borges' scrutinity, precisely to the theory contained in "Pierre Ménard, autor de Quixote", then it is concluded that this book must be considered a "translation" not a "writing".

Key-words: historical fiction, metafiction, Fernando Sabino.
\end{abstract}

\section{REFERÊNCIAS}

ADORNO, Theodor Wiesengrund. Adorno. São Paulo: Nova Cultural, 1996. (Os Pensadores).

BORGES, Jorge Luis. Obras Completas. São Paulo: Globo, 1999. v. 1. . Obras Completas. São Paulo: Globo, 1999. v. 2. 
. Obras Completas. São Paulo: Globo, 1999. v. 3.

. Prólogos con un prólogo de prólogos. Buenos Aires: Emecé, 1999.

ECO, Humberto. Seis passeios pelos bosques da ficção. São Paulo: Cia. das Letras, 1994.

HUTCHEON, Linda. Poética do pós-modernismo: história, teoria, ficção. Rio de Janeiro: Imago, 1991.

LAGES, Susana Kampff. Walter Benjamin: tradução e melancolia. São Paulo: Edusp, 2002.

LIMA, Rogério. O dado e o óbvio - o sentido do romance na pós-modernidade. Brasília: Ed. UNB/Universa, 1998.

MACHADO DE ASSIS, Joaquim Maria. Memorial de Aires. São Paulo: Ática, 2000.

. Dom casmurro. São Paulo: Moderna, 1983.

. Memórias póstumas de Brás Cubas. 5. ed. São Paulo: FTD, 1998.

- Quincas Borba. São Paulo: Moderna, 1994.

. Esaú e Jacó. São Paulo: Gráfica Ed. Brasileira, 1962.

. Os melhores contos - Machado de Assis. Seleção Domício Proença Filho. 11. ed.

São Paulo: Global, 1997.

MONTELLO, Josué. Memórias póstumas de Machado de Assis. Rio de Janeiro: Nova Fronteira, 1997.

PÓLVORA, Hélio. Capitu: Inocente ou Culpada? Disponível em: <http:// www.secrel.com.br/jpoesia/polvora04.html> Acesso em: 27 ago. 2002.

PERRONE-MOISÉS, Leyla. Altas literaturas: escolha e valor na obra crítica de escritores Modernos. São Paulo: Cia. das Letras,1998.

PRADO, Décio de Almeida. A personagem no teatro. In: CANDIDO, Antonio. (Org.). A personagem de ficção. São Paulo: Perspectiva, 1968.

SABINO, Fernando. Amor de Capitu. São Paulo: Ática, 1998.

SCHWARZ, Roberto. Ao vencedor as batatas. São Paulo: Duas Cidades, 1977.

. Cultura e política. São Paulo: Paz e Terra, 2001. 